Chapter 3

\title{
Close Neighbours on Chromosome 2 the ALK and MYCN Genes. Implications for Targeted Therapeutics in Neuroblastoma
}

\author{
Fergal C. Kelleher \\ Additional information is available at the end of the chapter \\ http://dx.doi.org/10.5772/55300
}

\section{Introduction}

Neuroblastoma is a neural crest-derived embryonal malignancy of the postganglionic sympathetic division of the peripheral autonomic nervous system. It is the most frequent extra cranial solid malignancy of childhood and the most common cancer in children less than one year of age. It accounts for $7 \%$ of childhood cancers and $15 \%$ of all childhood cancer deaths. It most commonly occurs sporadically but familial cases can also occur with one subdivision attributable to germline mutation of the PHOX2B gene and another due to germline ALK gene mutations $[1,2,3,4]$. Recurring chromosomal aberrations are detected in this disease and three major genomic subdivisions represent greater than $80 \%$ of cases; i.e. hyperdiploid neuroblastoma; near diplod neuroblastoma that has 17q gain and 11q deletions; and MYCN amplified neuroblastoma with $17 q$ gain and $1 p$ deletion $[5,6,7,8]$. A whole-genome analysis and assessment of structural defects in 87 primary neuroblastomas found few recurrent amino-acid changing mutations, with ALK mutations in 6\%, but identified local shredding of chromosomes (chromothripsis) in 18\% of high stage neuroblastomas. High stage tumours that did not have amplifications of MYCN had recurrent structural alterations in genes involved in cone stabilisation and neuritogenesis [9]. Indeed in this study tumours with a genomic signature involving defective genes responsible for neuritogenesis or growth cone guidance were mostly aggressive high-stage tumours.

Activating mutations of the anaplastic lymphoma kinase (ALK) genes and amplification of the MYCN oncogene can occur in neuroblastoma. The ALK gene resides on chromosome 2p23 centromeric to the MYCN locus on chromosome 2q24. Approximately 2-3\% of cases of neuroblastomas have amplification of ALK and these occur almost invariably concomitant 
with amplification of MYCN [10]. However, amplification of the ALK gene without concomitant MYCN gene amplification can occur, for example a particularly informative case of a neuroblastoma with a high level amplicon involving and solely limited to the ALK gene was described by French investigators in 2008 in one of the landmark papers that established the importance of ALK in neuroblastoma [11]. Activating ALK mutations are found in $80 \%$ of familial cases and $6-11 \%$ of sporadic cases. It is considered that once the expression of wild type ALK exceeds a certain threshold it can have oncogenic activity[10]. Twenty percent of all cases of neuroblastomas have amplification of MYCN which is associated with a worse prognosis and can be used to stratify treatment. This chapter appraises the current knowledge and potential therapeutic implications arising from ALK and MYCN abnormalities in neuroblastoma. In a concluding reflection the chromosomal proximity and interaction of these genes as well as the potential for therapeutic advancement in neuroblastoma is discussed.

\section{The anaplastic lymphoma kinase gene in neuroblastoma}

\subsection{The ALK gene}

The anaplastic lymphoma kinase gene is a 200kDa member of the insulin receptor super family. It is an orphan tyrosine kinase receptor and has homology with the MET oncogene and the neurotrophin receptor. It is normally expressed by the developing nervous system and at a much lower level in the nervous system of adults [12]. In mouse embryo studies Alk transcripts were detected in the central nervous system (CNS) and peripheral nervous system. E15 embryos had expression in the Gasserian ganglion of the trigeminal nerve (cell bodies of $\mathrm{V}_{1}$, $\mathrm{V}_{2}$ and sensory component $\mathrm{V}_{3}$ ) as well as the superior cervical ganglion, posterior root ganglia of the spinal cord and the myenteric plexus of the enteric nervous system. In the 1 week old mouse Alk transcripts are clustered in particular neuronal regions in the CNS such as the mesencephalon, thalamic nuclei which act as relay stations for nerve impulses and olfactory bulb, mitral cells and tufted cells that receive primary afferents from olfactory epithelial neurones. Relatively high levels of Alk transcripts were present in the superior colliculus, which is the centre of visual sensation and the red nucleus, a crucial part of the rubrospinal tract which regulates the contraction of flexor muscles [13]. Lower levels were detected in the hypothalamus, inferior colliculus, subiculum, cerebral cortex and cerebellum (Purkinje's cells and Golgi cells). Interestingly one patient in a phase 1 study of an ALK inhibitor in children with relapsed/refractory ALK-driven tumors (57 evaluated for toxicity) developed grade 3 dizziness [14]. It remains speculative as to whether it is possible to attribute it to cerebellar Alk expression based on the finding of low level Alk expression in the murine cerebellum.

The anaplastic lymphoma kinase gene has a restricted pattern of expression in adults in that it is expressed in testis, small intestine and brain but is not expressed in normal lymphoid tissue. It has been shown to be important in the pathogenesis of ALK positive anaplastic large cell lymphoma, inflammatory myofibroblastic tumours and adenocarcinoma of the lung (NSCLC) [15]. Its importance in cancer was first described in 1994 in anaplastic large cell lymphoma where a translocation $(2 ; 5)$ (p23; q35) fuses NPM a non-ribosomal nucleolar 
phosphoprotein with ALK in 50-75\% of cases [16]. The most frequent abnormality involving ALK in non-small cell lung cancer is an inversion of a segment of chromosome 2 creating a chimeric fusion gene involving ALK and the Echinoderm microtubule-associated protein; ALK-EML4 [17]. In inflammatory myofibroblastic tumours, tropomyosin TMP3 or TMP4 create fusion oncoproteins with ALK. Clonal rearrangements at chromosome 2p23 occur in $50 \%$ of these tumours [18]. More recently ALK protein expression has been seen in rhabdomyosarcomas with $81 \%$ of cases of the alveolar subtype having strong cytoplasmic staining for ALK compared to $31 \%$ of cases of the embryonal subtype. These subtypes have gene copy number gain of $88 \%$ and $52 \%$ respectively. In the embyonal subgroup ALK aberrations were associated with disease progression and outcome [19].

The ALK receptor is a dependence receptor and in the absence of ligand enhances apoptosis by autologous cleavage by caspase [12]. Therefore ALK belongs to the subcategory of oncogenes in which inappropriate expression in a cellular context or in the absence of ligand can induce apoptosis. This is considered to be a mechanism to abrogate frequent tumour formation if oncogenes become deregulated. Myc is also considered to be an established comparator gene in this respect. Additionally in the visual system of Drosophila ALK in the presence of a ligand appears essential for axonal guidance. It is known that perturbations of the visual system, in particular in the first 5 years of life can cause amblyopia [20,21]. Also, in an expanded cohort study of 82 adults with ALK positive NSCLC treated with crizotinib, mild visual disturbances were reported by $41 \%$ of patients. These were most frequently described as trails of light following moving objects particularly seen with changes in ambient lighting usually improving with duration of time receiving treatment [22]. It may be the case that the aforementioned finding of Alk transcripts in the superior colliculus of the 1 week old mouse is relevant as the superior colliculus is important for saccadic and smooth pursuit eye movements. Though not described to date in patients with neuroblastoma treated with ALK inhibitors, given the age demographics of patients with neuroblastoma it is the author's contention that clinicians conducting ongoing trials need to be cognisant of the theoretical potential to damage the developing neuroanatomical visual system with resulting amblyopa. The visual system includes the optic nerves, optic chiasma and optic tracts; the lateral geniculate body a swelling beneath the posterior projection of the pulvinar of the thalamus and the geniculoclcarine tract which originates within the lateral geniculate body and terminates at the calcarine sulcus of the medial surface of the cerebral hemisphere. Evaluation of the regional ALK status of this system is a subject for further research.

\subsection{ALK in neuroblastoma}

Neuroblastoma is considered to be a malignancy derived from the embryonic neural crest. Evidence of neuroblastoma being derived from neural crest progenitor cells are (i) neuroblastoma primary sites are anatomically consistent with arising from the sympatho-adrenergic lineage of neural crest differentiation (ii) The gene expression patterns of neuroblastomas and neural crest progenitor cells are similar [23] (iii) In situ neuroblastomas occur in the adrenal glands of $1 / 200$ newborns with most spontaneously regressing later in life and there is a histological similarity to residual nests of sympathogonia [24]. 
A small proportion of cases of neuroblastoma display autosomal dominant Mendelian inheritance patterns and a familial history of neuroblastoma is elicited in $1-2 \%$ of cases $[25,26$, 27]. There is a standardized incidence ratio of 9.7 for disease occurrence in siblings of index cases [28]. Previously it had been recognized that neuroblastoma can arise in the context of concurrent neurocristopathies related to abnormal development of neural-crest derived tissues such as concomitant Hirschsprung's disease or central congenital hypoventilation syndrome. Nonsense and missense mutations of the homeobox gene PHOX2B were shown to predispose to this abnormality of the sympathoadrenal lineage [4, 29, 30].

In October 2008 four articles were published in the journal Nature that established the importance of aberrations in ALK as a feature of some neuroblastomas [11,31,32,33]. Mossé and colleagues of Children's Hospital Philadelphia found that ALK is a major neuroblastoma predisposition gene with germline ALK mutations accounting for most cases of familial neuroblastoma [31]. Using a whole-genome scan of neuroblastoma pedigrees (8 unrelated families) a significant linkage signal at 2p23-24 was identified. Re-sequencing 194 high risk neuroblastomas found somatically acquired ALK mutations in $12.4 \%$ of cases. Most mutations mapped to the kinase domain of ALK and caused constitutive phosphorylation. Cell line studies also showed that knockdown of ALK mRNA caused growth inhibition suggesting that therapeutics targeting ALK may have clinical efficacy in neuroblastoma.

In another study lead by investigators at Dana Farber Cancer Institute, Boston mutations of ALK were found in $8 \%$ of primary neuroblastomas [32]. A genome wide study of primary neuroblastomas identified amplification of the ALK gene. Analysis of 94 tumours with amplification of MYCN found 14 (15\%) with concomitant ALK amplification. This was not identified in 51 tumors without MYCN amplification. DNA resequencing of the ALK open reading frame identified in primary neuroblastomas found 5 non-synonymous sequence variations in the ALK tyrosine kinase domain in 7 of 93 samples (8\%). The most frequent mutation which was in $4.3 \%$ (4) of the 93 cases was a cytosine to adenine alteration in exon 23 causing a phenylalanine to leucine substitution in codon 1174 (F1174L). This mutation was also found in 3 different neuroblastoma cell lines. Three of the mutations were somatic and 2 were germline. Interestingly 4 of the 5 identified mutations involved residues which correspond to those that are affected by activating EGFR gene mutation. The ALK 1174 residue correlated with V769 in EGFR and ERBB2 [34]. A F1245C ALK mutation correlated with the L833V mutation in EGFR, which is a gefitinib resistant mutation in NSCLC. The R1275Q mutation is positioned adjacent to the homologous position of L858R in EGFR, the most common mutation of EGFR in NSCLC $[35,36]$. ALK cDNA encoding either the F1174L or the R1275Q variants transformed interleukin-3 dependent murine hematopoietic Ba/F3 cell lines to cytokine independent cell growth. Furthermore these autonomously growing cells were sensitive to the ALK inhibitor TAE684. Additionally 2 human neuroblastoma cell lines were sensitive to TAE684. It has been observed by Mossé and colleagues that there are disorder involving oncogenes such as RET in medullary thyroid cancer arising in the context of multiple endocrine neoplasia type 2 and MET in papillary carcinoma of the kidney that are analogous to the sequential 'two hit model' of Knudson. Knudsons' was first used to describe retinoblastoma arising from aberrations of a tumor suppressor gene. In the oncogene 'two hit' model the 
second hit is a somatically acquired duplicate of the mutant allele or mutant gene amplification [37]. In neuroblastoma oncogenic activation of ALK can occur by mutation of the tyrosine kinase domain and for example with respect to a 'second hit' in the Dana Farber led study, ALK gene amplification was found in 15\% of 94 tumours with MYCN amplification.

French investigators assessed ALK copy number variation by comparative genomic hybridization in 592 cases of neuroblastomas [11]. Within this group 26 cases (4.4\%) had in excess of a twofold copy number increase of ALK and a further 135 cases $(22.8 \%)$ had lower level gains. The level of expression of ALK is strongly correlated with copy number [38]. Within the genomic analysis a subcategory without MYCN amplification was assessed using 100K single nucleotide polymorphism arrays. A notable case within this cohort was an instance of neuroblastoma with a high level amplicon involving and solely limited to the ALK gene. Also a series of 28 cell lines and 115 tumor samples found 16 ALK mutations grouped into 2 main hotspots. The F1174L mutation was seen in one primary tumor but was more frequent in cell lines suggesting that this particular mutation confers an in vitro growth advantage. Cell lines are usually over-represented by metastatic tumors with a greater propagating potential and this finding may be vicarious evidence of the F1174L mutation being correlated with a poorer clinical outcome. Finally a Japanese study identified 8 novel missense mutations in the ALK gene in 13 out of 215 cases of neuroblastoma (6.1\%) and 8 of $33(33 \%)$ neuroblastoma cell lines. The mutated kinases could transform NIH3T3 fibroblasts and form tumors in nude mice [33].

These four studies were a landmark advance in the field, however later a European group of international collaborators performed a meta-analysis of 709 neuroblastomas ( 254 new cases and 455 previously published) to comprehensively described the correlation of ALK mutation type and frequency with clinical and genomic factors. They also assessed the prognostic significance of ALK copy number and expression [39]. Mutations in ALK were detected in $6.9 \%$ of cases with a mutation frequency of ALK of $5.7 \%$ in favorable (International neuroblastoma Staging System INSS 1, 2 and 4s) cases and 7.5\% in unfavorable tumors (INSS 2 and 4). There was no statistical difference with respect to mutation frequency between the favorable and unfavorable groups ( $\mathrm{P}=0.087$ ). Mutation hot spots R1275Q (49\%) and F1174L (34.7\%) were observed within the mutated cases. However the F1174L mutations occurred in a greater proportion of the MYCN amplified cases $(\mathrm{P}=0.0001)$ and the concurrence of a F1174L mutation in a MYCN amplified neuroblastoma was found to confer an especially poor prognosis. It was described that there was a skewed ALK mutation spectrum within the MYCN amplified cohort with over-representation of the F1174L mutation. F1174 mutated ALK was present in $1.3 \%$ of single copy MYCN tumors compared with $6.1 \%$ of MYCN amplified tumors. To consider it another way, within the 17 cases of F1174 ALK mutated neuroblastoma 58.8\% had amplification of MYCN compared to a rate of $21.6 \%$ in cases of neuroblastoma with wild type ALK. There also was no difference in the frequency for MYCN amplification between the R1275Q cases and wild type ALK. The skewed distribution of F1174L mutations being overrepresented in MYCN amplified cases of neuroblastoma was also confirm in 27 neuroblastoma cell lines most of which were MYCN amplified. Five had the F1174L mutation with only one case of R1275Q mutant neuroblastoma found. F1174 mutated neuroblastoma compared to the R1275Q 
mutant variant had a greater transforming ability with a higher amount of auto phosphorylation. Gain in Chr. 2p that included ALK (91.8\%) also was correlated with poor survival.

\subsection{Possible new treatments for neuroblastoma that target ALK}

Crizotinib is an orally bio-available small molecule that inhibits the tyrosine kinase activity of ALK and c-Met which is approved by the U.S. Food and Drug administration for the treatment of cases of NSCLC that have rearrangements of the ALK gene. Crizotinib competes with adenosine triphosphate to bind to the ALK tyrosine kinase. The two most common ALK mutations in neuroblastoma are F1174L and R1275Q and both mutations promote autophosphorylation of the ALK tyrosine kinase region. F1174 mutated ALK in particular is a more lethal variant. Using neuroblastoma cell lines and xenograft models it has been shown that different ALK mutations can affect both kinase activity and inhibitor sensitivity [40]. Both F1174L and R1275Q ALK mutations cause amino acid substitutions in the intracellular tyrosine kinase domain of the ALK receptor and constitutively activate the ALK tyrosine kinase domain. Neuroblastoma cell lines and xenograft mouse models that expressed R1275Q-ALK are sensitive to crizotinib. By comparison F1174L mutated ALK cell lines were relatively resistant to crizotinib. The $\mathrm{K}_{\mathrm{m} \text {, ATP }}$ for F1174L of $\sim 0.127 \mathrm{Mm}$ was approximately 2.3 times lower than the $\mathrm{K}_{\mathrm{m} \text {, ATP }}$ of 0.326 for the R1275Q mutant ALK variant. The F1174L mutation combines the characteristics of an activating gene mutation and a resistance mutation, increasing $\mathrm{k}_{\mathrm{cat}}$ and maintaining a wild type like $\mathrm{K}_{\mathrm{m} \text {, ATP }}$. The derived overall inference of these findings is that comparative crizotinib resistance of the F1174L mutant ALK is due to greater ATP binding affinity and it is hoped that the resistance may be overcome by increasing the doses of crizotinib or using ALK inhibitors with increased affinity to the ALK tyrosine kinase domain.

The U.S. National Cancer Institute is sponsoring a phase I/II study of crizotinib in children with relapsed or refractory solid tumors and anaplastic large cell lymphoma. The phase I study was presented at the American Society of Clinical Oncology Annual Meeting in Chicago, June 2012 (Protocol IDs: COG-ADVL0912, ADVL0912, NCT00939770) by Yael Mossé; abstract 9500 [14]. The study enrolled 70 patients with confirmed ALK fusion proteins, mutations or amplification with 57 fully evaluable for toxicity. This was a heterogeneous study population with respect to cancer type and included other cancers in addition to neuroblastoma. Six different dose levels of crizotinib were evaluated using the rolling-six design and dosing was bid on 28 day cycles without interruption. The recommended phase II dose that emerged was $280 \mathrm{mg} / \mathrm{m}^{2} /$ dose. Seven of eight $(88 \%)$ of patients with anaplastic large cell lymphoma had a complete response ( 2 differing dose levels). 27 patients in the trial had neuroblastomas. Within the cohort of neuroblastoma cases with a known ALK mutation $(n=8)$, one patient had a complete response and 2 had stable disease. Of the 19 patients with neuroblastoma and an unknown ALK status, 1 had a complete response and 6 had prolonged stable disease.

With respect to toxicity there were two grade 5 cases of haemorrhage within the central nervous system in patients with neuroblastoma and the protocol was updated to exclude patients with a previous history of central nervous system involvement. Other toxicities observed within the study and not necessarily within the neuroblastoma subgroup were grade 4 transaminitis $(n=1)$, grade 4 neutropenia $(n=1)$ and grade 3 dizziness $(n=1)$. A discussant at the meeting 
Thomas Gross of The Ohio State University Nationwide Children's Hospital referenced some Crizotinib toxicities observed in adults with NSCLC including gastrointestinal complaints, transient vision disorders, self-limited lower testosterone levels and rare renal cysts. He felt that these toxicities necessitated further investigation in the paediatric population. Regarding efficacy he noted that there can be variability in oncogenic partners with ALK within chimeric fusion genes in differing disease types that may partly account for the rates of complete responses seen in different malignancies. He also observed that some responses were seen in ALK negative cases in the phase 1 trial. Phase II data on the efficacy and toxicity of Crizotinib in neurblastoma will be required.

\section{The MYCN gene in neuroblastoma}

\subsection{The MYCN family}

MYC is a pleotropic evolutionary conserved family of basic helix-loop-helix leucine zipper transcription factors, comprising c-Myc, L-Myc and N-Myc [41, 42]. These transcription factors regulate the expression of $\sim 15 \%$ of all genes $[43,44]$. MYC proteins have numerous roles in malignancy with roles of special importance in neuroblastoma being that of driving cellular proliferation and angiogenesis while concurrently inhibiting apoptosis and maintaining the neoplastic 'stem cell' compartment. MYCN is amplified in $20 \%$ of cases of neuroblastoma and amplification of MYCN is independently correlated with a higher disease stage and a poor clinical outcome. It is amplified in $40 \%$ of cases with a high risk phenotype. It has been contended that targeting Myc is a therapeutically attractive strategy to treat cancer but difficulties persist. These include (i) Myc exerts effects by protein-protein and protein-DNA interactions. Small molecule inhibitors have not usually been effective in this context. (ii) Most Myc aberrations in malignancies are not due to intrinsic abnormalities of Myc but rather due to 'upstream' aberrant oncogenic signals causing it's induction (iii) Myc is required for stem cell compartment maintenance and proliferation in normal tissues with a theoretical concern of serious bystander tissue toxicities [45] (iv) Analysis of the role of c-Myc and N-Myc in cancer is difficult to assess in tissues as embryonic lethality is conferred by germline deletion of these genes. Much of the data on the consequences of inhibiting Myc is derived from conditional knockouts of the c-Myc gene using Cre mediated recombination which can be very variable and unpredictable in the extent of c-myc deletion in the cells targeted (iv) Conditional knockout models are irreversible and therefore not good representative models of transient inhibition of Myc conferred by inhibitor medications.

One particularly important experimental example of Myc inhibition was in an adenocarcinoma of lung murine model [45]. Omomyc is a competitive inhibitor of Myc-dependent gene transcription by preventing the binding of Myc to its consensus E-box CACGTG DNA elements thereby preventing Myc binding to its obligate dimerization partner Max. This prevents the transactivation of its target genes. Omomyc may also augment Myc-dependent trans repression [46, 47]. The LSL-Kras ${ }^{\mathrm{G} 12 \mathrm{D}}$ murine model of NSCLC has irreversible activation of oncogenic $\mathrm{KRas}^{\mathrm{G} 12 \mathrm{D}}$ driven by the kras promoter when it inhales adenovirus expressing Cre recombinase. 
This causes multifocal lung tumours to occur within 18 weeks. Shut down of Myc transactivation using transgenic Omomyc expression caused profound tumour reduction within 3 days and mice become overtly tumour free after 28 days [45]. Reassuringly murine tissue integrity was maintained with no major unexpected toxicities emerging. Considering neuroblastoma, treatments directed at MYCN are particularly appealing as genetic mouse models with MYCN targeted to neural crest tissue develop tumours which are similar to neuroblastomas [48].

\subsection{MYCN in neuroblastoma}

Double minutes and homogeneously staining regions are the cytogenetic hallmarks of genomic amplification in malignancies. Neuroblastoma karyotyes frequently have these cytogenetic markers and MYCN amplifications are often found [49]. Tumours that have an aggressive phenotype frequently have amplification of the MYCN oncogene and amplification of MYCN is correlated with the extent of disease at diagnosis [50]. Correlative International Neuroblastoma Staging System (INSS) stage at diagnosis and the respective frequency of MYCN amplification described by data from the Children's Oncology Group Statistical Office are; Stage 1,3\%; Stage 2a/2b, 4\%; Stage 3, 25\%; Stage 4, 32\% and Stage 4s, 8\% (Wendy, London; John, Maris, Principles and Practice of Paediatric Oncology, page 890). Amplification of MYCN is normally detected by interphase FISH with a usual increase in copy number of 50 to 400 copies in neuroblastomas and a cut off of 4 times the normal copy number being the definition of MYCN amplification by many pathologists. Other genes can be co-amplified with MYCN $[51,52]$. Also comparative genomic hybridisation of tumours arising in a transgenic mouse model that overexpresses MYCN in neuroectodermal cells, found losses and gains of at least seven chromosomal regions. These were syntenic with comparable abnormalities detected in human neuroblastomas [52].

NVP-BEZ235 a dual inhibitor of the phosphatidylinositol 3-kinase (PI3K)/mammalian target of rapamycin (mTOR) pathway decreases levels of MYCN protein and suppresses tumour proliferation and angiogenesis in neuroblastomas [53]. This partly arises because MYCN in tumour cells contributes to paracrine signalling between tumour cells and endothelial cells. It has previously been shown that blocking PI3K/mTOR causes destabilisation of MYCN protein with reduced VEGF secretion and inhibition of progression of neuroblastomas in murine models [54]. A study published in Science Translational Medicine in 2012 by Chanthery and colleagues provided new information as to the separate 'intrinsic' and 'paracrine' including 'anti-angiogenic' mediated anti-tumour effects of inhibiting PI3K/mTOR signalling in neuroblastomas using NVP-BEZ235. Improved survival was seen in two mouse models, the first a xenograft tumour derived from a patient (MYCN-amplified human orthoptic xenograft) and the second a MYCN dependent transgenic model (transgenic for TH-MYCN; that recapitulates a MYCN amplified tumour arising in an autochthonous site) in which MYCN causes spontaneous tumour formation in mice. In both models there were reductions in tumour growth without tumour regression. This was attributed to a reduction in proliferation of neuroblasts and decreased tumour vascular density. PI3K inhibition caused de-repression of GSK3 $\beta$ with consequential Thr58 phosphorylation and destabilisation of MYCN with a remarkable reduction in MYCN levels in tumours treated with NVP-BEZ235. 
To establish tumour cell autonomous effects of NVP-BEZ235 on MYCN degradation, HUWE1 knockdown tumour cells (deficient in PI3K/mTOR-mediated MYCN proteolysis; a Thr58 mutant MYCN) were used to establish orthoptic xenograft models. It was demonstrated that HUWE1 were resistant to the anti-angiogenic effects of NVP-BEZ235 showing that MYCN was a critical target in vivo and part of the anti-angiogenic effect is a consequence of the transcription regulatory function of MYCN. It is possible that NVP-BEZ235 may emerge as a new therapeutic choice for the treatment of neuroblastoma.

\section{ALK and MYCN}

\subsection{ALK and MYC co-operating neighbours}

ALK and MYCN are the only established oncogenes in neuroblastoma [55, 56]. ALK mutations occur at an equal frequency in both low and high risk neuroblastomas and within all genomic subtypes which is suggestive that mutations within the ALK gene are not the only molecular aberrations that drives oncogenesis in this disease [57]. ALKF1174L mutated neuroblastomas are more common within the high risk neublastoma category [10]. In neuroblastoma cell line studies overexpression of wild type or mutated ALK stimulates the transcription of MYCN and the concurrent expression of MYCN and activated ALK increases the in vitro transformation of NIH3T3 cells [58].

A series of experiments on pathogenic cooperation between ALK and MYCN were conducted using a transgenic zebrafish model of neuroblastoma in which MYCN induced tumour arose from a subpopulation of neuroblasts which migrate to the interrenal gland, the zebrafish equivalent of the adrenal medulla (50\% of neuroblastomas in humans arise in the adrenal medulla) [59]. Sympathoadrenal precursors in the interrenal gland co-express the cholaminergic enzymes tyrosine hydroxylase and dopamine- $\beta$-hydroxylase as well as neuronal specific Hu proteins. In this model the dopamine- $\beta$-hydroxylase promoter was used to drive EGFR-MYCN expression. Using this experimental model it was found that $17.3 \%$ of MYCN induced zebrafish develop neuroblastomas. Transgenic zebrafish that expressed wild type ALK or that expressed F1174L mutant ALK did not develop neuroblastomas. Activated ALK accelerate the onset of neuroblastoma and increased the penetrance of MYCN-induced neuroblastoma with a 3 fold increase for fish co-expressing both MYCN and ALK F1174L compared to wild type or F1174L mutant ALK fish. The mechanism as to how neuroblastomas arise within the zebrafish model was also investigated. MYCN overexpressing transgenic fish has an increased number of $\mathrm{Hu}^{+}$neuroblasts that fail to differentiate resulting in increased cell number with reduced numbers of chromaffin cells compared to controls at 3-5 weeks post fertilization (wpf). An apoptotic response significantly reduced the number of these $\mathrm{Hu}^{+}$cells at the 5-7 wpf interval. In the presence of a cooperating activated ALK there is continuous accumulation of $\mathrm{Hu}+$ neuroblasts with failure of differentiation but there is decreased apoptosis of high penetrance and transformed neuroblastoma. Overall it has been inferred that ALK mutant F1174L attenuates the sequential apoptotic response in MYCN transformed $\mathrm{Hu}+$ 
neuroblasts constituting the 'second' hit when considering it as an oncogenic equivalent of the Knudson 'two hit' model.

Another study found that ALK regulates the initiation of MYCN transcription in neuroblastoma [58]. ALK (including wild type ALK and mutated variants) stimulated the transcription of MYCN mRNA by affecting the MYCN promoter in neuronal and neuroblastoma cell lines. Similarly the transcription of MYCN can be abrogated by using ALK inhibitors such as crizotinib or NVP-TAE684. A series of experiments found that $\mathrm{ALK}^{\mathrm{F} 1174 \mathrm{~L}}$ or $\mathrm{ALK}^{\mathrm{R} 1275 \mathrm{Q}}$ mediated a marked transformation of NIH3T3 cells but MYCN alone or wild type ALK failed to initiate cellular transformation. Co-transfection of ALK ${ }^{1174 \mathrm{~L}}$ concurrent with MYCN caused a 3 fold increase in transformation compared to activated $\mathrm{ALK}^{\mathrm{F} 1174 \mathrm{~L}}$ alone. Results consistent with this finding were seen when $\mathrm{ALK}{ }^{\mathrm{R} 1275 \mathrm{Q}}$ was expressed with $\mathrm{MYCN}$. It was consistently noted that $\mathrm{ALK}^{\mathrm{F} 1175 \mathrm{~L}}$ has a greater transforming potential than $\mathrm{ALK}^{\mathrm{R} 1275 \mathrm{Q}}{ }^{60}$. Overall it appears that ALK drives the initiation of MYCN transcription. Concomitant expression of a constitutively active mutant ALK variant causes increased transformation and MYCN protein levels compared with expression of $\mathrm{ALK}^{\mathrm{F} 1174 \mathrm{~L}}, \mathrm{ALK} \mathrm{K}^{\mathrm{R} 1275 \mathrm{Q}}$ or MYCN alone. Trials of ALK inhibitors alone in neuroblastoma may not succeed as dysregulation of MYC is the main 'oncogenic driver' in the disease and initiation of MYCN transcription can occur by ways other than by the mutation or amplification of ALK.

\section{Recent therapeutic advances in neuroblastoma and the promise of targeted therapies changing the treatment paradigm}

The treatment of neuroblastoma varies according to risk group stratification and prognosis. Therefore prognosis needs to be considered first prior to contextualizing recent therapeutic advances.

\subsection{Prognosis}

Phenotypic and prognostic variation occurs in neuroblastoma as some clinical phenotypes spontaneously regress while other patients have rapidly progressive high risk disease in which despite intensive myeloablative chemotherapy relapses are common and almost invariably fatal [61,62]. Neuroblastoma prognosis can be subdivided into low risk, intermediate risk, high risk, and stage 4S disease [63]. The U.S. National Cancer Institute also has listed different subdivisions of neuroblastoma. Firstly neuroblastomas can be subdivided into three biologically discrete types of tumor. These categories can be used to sub-stratify patient prognosis but do not have treatment implications $[64,65]$.

Type 1: Hyperdiploid, expression of TrkA neurotropin receptor. Tends to spontaneously regress.

Type 2: Expression of TrkB neurotropin receptor and its ligand. Additional copy of chromosome $17 q$, loss of heterozygosity $14 q$ or $11 q$. Genome unstable.

Type 3: Gain chromosome 17q, loss of chromosome 1p, MYCN amplification. 
There also is a risk assignment system in North America that has been used clinically by the Children's Oncology Group in studies such as COG-9641 and COG-A3961 [66, 67]. It has categories of low, intermediate and high-risk based on INSS stage, age, and tumor biology. Tumor biology characteristics considered are International Neuroblastoma Pathologic Classification (INPC), MYCN status and tumor DNA index. The INPC system involves the evaluation of pre-treatment tissue for the amount of stromal development, the mitosiskaryorrhexis index and the degree of neuroblastic maturation [68,69,70,71]. Stage $4 \mathrm{~S}$ disease though included in these studiers is a particular case.

\subsubsection{Treatment advances in high risk neuroblastoma in the 'ALK Era'}

In 2009 long term outcomes of 379 patients with high risk neuroblastoma (CCG-3891) all of whom received the same induction treatment ( 5 cycles' cisplatin, doxorubicin, etoposide and cyclophosphamide plus surgery and received radiotherapy for residual local and metastatic disease) was reported [72]. Subsequent to induction patients were randomly assigned to consolidation with myeloablative chemotherapy, total body irradiation, and autologous purged bone marrow transplantation versus 3 cycles of intensive chemotherapy (cisplatin, etoposide, doxorubicin and ifosfamide). Of the participants that completed consolidation without disease progression, they were randomly assigned to no further therapy or 6 cycles of 13 -cis retinoic acid $\left(160 \mathrm{mg} / \mathrm{m}^{2} / \mathrm{d}\right.$ in 2 divided doses for 14 days every 28 days). Myeloablative therapy and autologous hematopoietic rescue had a significantly better 5 year event free $(\sim 30 \%$ versus $\sim 19 \%$ ) and overall survival compared with non-myeloablative chemotherapy. 13 cisretinoic acid after consolidation independently lead to significantly improved overall survival. 5 year overall survival from time of second random assignment for patients who underwent both sequential randomisations is documented in table 1.

\begin{tabular}{|c|c|}
\hline Treatment randomly assigned to & 5-year overall survival \\
\hline ABMT / 13-cis retinoic acid & $59 \%+/-8 \%$ \\
\hline ABMY / no 13-cis retinoic acid & $41 \%+/-7 \%$ \\
\hline Continuing chemotherapy / 13-cis retinoic acid & $38 \%+/-7 \%$ \\
\hline Chemotherapy / no 13-cis retinoic acid & $36 \%+/-7 \%$ \\
\hline
\end{tabular}

Table 1. please add caption

In 2010 a new treatment advance was reported in high risk neuroblastoma involving ch14.18 a chimeric human-murine anti-GD2 monoclonal antibody that targets GD2 a disialoganglioside tumour associated antigen [73]. Patients that had a response to induction therapy and stem-cell transplantation were treated with immunotherapy (six cycles of isotretinoin and five concomitant cycles of ch14.18 in combination with alternating GM-CSF and interleukin-2). This regimen was found to be better than standard treatment ( six cycles of isotretinoin) with a 2 year event free survival rate of $66 \%$ compared to $46 \%$ respectively, $\mathrm{P}=0.02$. 
High risk disease has a generic treatment paradigm of intensive chemotherapy to induce remission followed by surgery, radiotherapy and myeloablative chemotherapy. A presentation at the 2011 ASCO Annual meeting changed the treatment standard for high risk disease. The HR-NLB1 trial was a comparator trial between two high dose myeloablative chemotherapeutic regimens in high risk neuroblastoma. 563 children with stage IV disease (high risk distant metastatic disease or local disease; median age 3 years) received busulphan and myelphalan (281 patients) or a 3 drug chemotherapeutic combination of carboplatin, etoposide and melphalan (CEM; 282 patients). The 3 year event free survival was $49 \%$ versus $33 \%$ respectively. The 3 year overall survival was $60 \%$ versus $48 \%$ again favouring busulphan-melphalan over CEM. Busulphan-melphalan also had a lower rate of relapse $47 \%$ versus $60 \%$ [74].

\subsubsection{Intermediate risk neuroblastoma advances in the 'ALK Era'}

A phase 3 non randomized trial of newly diagnosed intermediate risk neuroblastoma without MYCN amplification was performed on 479 patients (323 patients had favourable biology tumours; 141 patients had tumours with unfavourable biology) [75]. Patients with favourable histopathology and hyperdiploidly received 4 cycles of chemotherapy (carboplatin, etoposide, cyclophosphamide and doxorubicin, administered at 3-week intervals) and patients with unfavourable features or an incomplete response received 8 cycles. The 3 year overall survival rate was $\sim 96 \%$ with an overall survival rate of $98 \%$ for patients with favourable biology tumour and $93 \%$ for patients with unfavourable biology neuroblastomas. Using this biologic based risk assignment high rates of survival were preserved in intermediate risk disease with reduced doses and duration of chemotherapy compared to historic controls (e.g. Children's Oncology Group trial CCG-3881; overall survival INSS stage 4s, 92\%; stage 4, 93\%; stage 3, $100 \%)[76,77,78]$. Recent years have seen advancements in high risk neuroblastoma involving myleoablative conditioning regimens, 13 -cis retinoic acid and immunotherapeutic. However in intermediate risk disease the evolution of treatment involves preservation of treatment efficacy using a biologically defined stratification approach with a reduction in the patient exposure to chemotherapy.

\subsubsection{What of ALK and MYC and targeted treatments?}

MYC gene transcription can be diminished by targeting BET bromodomainds using small molecular inhibitors of the BET family of chromatin adaptors [79]. Inhibition of BET bromodomain-promoter interactions with reduced MYC mRNA transcription and translation of MYC protein caused G1 cycle arrest with apoptosis in a diverse number of lymphoma and leukaemia cells. There was dysregulation of the MYC transcriptome including reactivation of the tumour suppressor p21. Treating xenograft models of Burkitt's lymphoma or acute myeloid leukaemia with a BET inhibitor demonstrated significant anti-tumour activity. Activation of the c-MYC gene is the sine qua non of Burkitt's lymphoma with the c-MYC locus at Chr. 8q24 involved in $\mathrm{t}(8 ; 14)(\mathrm{q} 24 ; \mathrm{q} 32)$ epidemic Burkitt's lymphoma and other abnormalities involving the MYC gene in sporadic cases including a different $t(8 ; 14)$ translocation and point mutation of exon 2 of c-MYC. In neuroblastoma cell lines with MYCN amplification high 
dose transient treatment with (+)-JQ1 (a small molecule enantiomer BET bromodomaine inhibitor) caused transcriptional repression of MYCN.

Zhu and colleagues in the zebrafish model of neuroblastoma show that ALK F1174L attenuates MYCN induced apoptosis [59]. Given the previous experience with targeted therapeutics in other disease types and the emergence of drug resistance it has been contended that responses to crizotinib are unlikely to be durable [57]. As ALK and MYCN have collaborative roles with MYCN being the primary oncogenic driver it may be the case that some of the initial optimism pertaining to Crizotinib in neuroblastoma may not be fulfilled and that dual targeting of ALK and MYCN once technically feasible may revolutionise the outcome for many patients with neuroblastoma. In a fascinating caveat it is notable that in MYCN single-copy cases of neuroblastoma, increased MYCN mRNA and protein levels are paradoxically associated with a more favourable clinical phenotype. Gene expression profiling of 251 primary neuroblastomas identified a core set of MYCN/c-MYC target genes with a successive gradual increase in that target gene signature in localized non-amplified cases to stage 4s-non amplified followed by stage 4-non-amplified and finally MYCN amplified cases. High expression of the MYCN/cMYC gene signature identified patients with poor overall survival independent of some of the usual clinico-pathologic variables such as age at diagnosis ( $>$ or equal 1.5 years; stage 4 versus stages 1,2,3, and 4s and amplified MYCN) [80]. It is apparent that MYCN's role in the quite heterogenous disease neuroblastoma is complex and the development of targeted therapeutics in neuroblastoma needs to appreciate these complexities. Of course treatments that target MYCN remain therapeutic lacunae to be filled. A final ancillary comment on ALK and MYC. German investigators have designed and performed experiments using JoMa1 which is a multipotent neural crest progenitor cell line that is kept in an undifferentiated but viable state by a tamoxifen activated c-Myc transgene (c-MycER ${ }^{\mathrm{T}}$ ) [81]. Expression of ALKF1174L in primary neuroblastomas caused in vitro growth of these cells independent of c-MycER ${ }^{\mathrm{T}}$ activity and the in vivo growth of neuroblastoma like tumours. Tumorigenicity was further enhanced by serial transplantation and remained susceptible to NBT-272 a MYC inhibitor. Therefore it appears that targeting ALK alone may result in regression of neuroblastoma with the potential to further augment tumour regression by inhibition of MYC. Maybenew hope for children with neuroblastoma does not fully rely on neighbourly gene relations!

\section{Conclusion}

The improvement in outcome in neuroblastoma treatment in recent decades is a tremendous success however outcomes for high risk disease have changed little. The importance of the ALK gene in this disease and an established ALK inhibitor already being used in other types of cancer offers new hope for improving outcomes. Therapeutic targeting of Myc is a long aspired for hope in the wider field of oncology which may be realised. Chromosomal proximity of genes such as topoisomerase II and Her-2 in breast cancer has been a topical subject but aside from the concept of co-amplification of genes as in the breast cancer 'topo II-Her2' paradigm ALK and Myc interact in many nuanced and therapeutically exploitable ways with the prospect of many advances still to come. 


\section{Author details}

Fergal C. Kelleher

Peter MacCallum Cancer Centre, Melbourne, Victoria, Australia

\section{References}

[1] Maris JM, Hogarty MD, Bagatell R, Cohn SL. Neuroblastoma. Lancet. 2007 Jun 23;369(9579):2106-20.

[2] Brodeur GM. Neuroblastoma: biological insights into a clinical enigma.Nat Rev Cancer. 2003 Mar;3(3):203-16.

[3] Tonini GP, Longo L, Coco S, Perri P. Familial neuroblastoma: a complex heritable disease. Cancer Lett. 2003 Jul 18;197(1-2):41-5.

[4] Trochet D, Bourdeaut F, Janoueix-Lerosey I, Deville A, de Pontual L, Schleiermacher G, Coze C, Philip N, Frébourg T, Munnich A, Lyonnet S, Delattre O, Amiel J. Germline mutations of the paired-like homeobox 2B (PHOX2B) gene in neuroblastoma. Am J Hum Genet. 2004 Apr;74(4):761-4.

[5] Vandesompele J, Baudis M, De Preter K, Van Roy N, Ambros P, Bown N, Brinkschmidt C, Christiansen H, Combaret V, Lastowska M, Nicholson J, O'Meara A, Plantaz D, Stallings R, Brichard B, Van den Broecke C, De Bie S, De Paepe A, Laureys G, Speleman $\mathrm{F}$. Unequivocal delineation of clinicogenetic subgroups and development of a new model for improved outcome prediction in neuroblastoma. J Clin Oncol. 2005 Apr 1;23(10):2280-99.

[6] Michels E, Vandesompele J, De Preter K, Hoebeeck J, Vermeulen J, Schramm A, Molenaar JJ, Menten B, Marques B, Stallings RL, Combaret V, Devalck C, De Paepe A, Versteeg R, Eggert A, Laureys G, Van Roy N, Speleman F. ArrayCGH-based classification of neuroblastoma into genomic subgroups. Genes Chromosomes Cancer. 2007 Dec;46(12):1098-108.

[7] Janoueix-Lerosey I, Schleiermacher G, Michels E, Mosseri V, Ribeiro A, Lequin D, Vermeulen J, Couturier J, Peuchmaur M, Valent A, Plantaz D, Rubie H, ValteauCouanet D, Thomas C, Combaret V, Rousseau R, Eggert A, Michon J, Speleman F, Delattre O. Overall genomic pattern is a predictor of outcome in neuroblastoma. J Clin Oncol. 2009 Mar 1;27(7):1026-33. Epub 2009 Jan 26.

[8] Brodeur GM. Molecular basis for heterogeneity in human neuroblastomas. Eur J Cancer. 1995;31A(4):505-10.

[9] Molenaar JJ, Koster J, Zwijnenburg DA, van Sluis P, Valentijn LJ, van der Ploeg I, Hamdi M, van Nes J, Westerman BA, van Arkel J, Ebus ME, Haneveld F, Lakeman A, 
Schild L, Molenaar P, Stroeken P, van Noesel MM, Ora I, Santo EE, Caron HN, Westerhout EM, Versteeg R. Sequencing of neuroblastoma identifies chromothripsis and defects in neuritogenesis genes. Nature. 2012 Feb 22;483(7391):589-93.

[10] Azarova AM, Gautam G, George RE. Emerging importance of ALK in neuroblastoma. Semin Cancer Biol. 2011 Oct;21(4):267-75. Epub 2011 Sep 16.

[11] Janoueix-Lerosey I, Lequin D, Brugières L, Ribeiro A, de Pontual L, Combaret V, Raynal V, Puisieux A, Schleiermacher G, Pierron G, Valteau-Couanet D, Frebourg T, Michon J, Lyonnet S, Amiel J, Delattre O. Somatic and germline activating mutations of the ALK kinase receptor in neuroblastoma. Nature. 2008 Oct 16;455(7215):967-70.

[12] Mourali J, Bénard A, Lourenço FC, Monnet C, Greenland C, Moog-Lutz C, RacaudSultan C, Gonzalez-Dunia D, Vigny M, Mehlen P, Delsol G, Allouche M. Anaplastic lymphoma kinase is a dependence receptor whose proapoptotic functions are activated by caspase cleavage. Mol Cell Biol. 2006 Aug;26(16):6209-22.

[13] Iwahara T, Fujimoto J, Wen D, Cupples R, Bucay N, Arakawa T, Mori S, Ratzkin B, Yamamoto T. Molecular characterization of ALK, a receptor tyrosine kinase expressed specifically in the nervous system. Oncogene. 1997 Jan 30;14(4):439-49.

[14] Mosse YP, Balis FM, Lim MS, Laliberte J, Voss SD, Fox E, Bagatell R, Weigel B, Adamson PC, Ingle AM, Ahern CH, Blaney S; The Children's Hospital of Philadelphia, Philadelphia, PA; C S Mott Children's Hospital, Ann Arbor, MI; Children's Hospital of Boston, Boston, MA; Children's Hospital of Philadelphia, Philadelphia, PA; University of Minnesota, Minneapolis, MN; Children's Oncology Group, Arcadia, CA; Baylor College of Medicine, Houston, TX; Texas Children's Cancer Center, Houston, TX. Efficacy of crizotinib in children with relapsed/refractory ALK-driven tumors including anaplastic large cell lymphoma and neuroblastoma: A Children's Oncology Group phase I consortium study. Abstract No: 9500; J Clin Oncol 30, 2012 (suppl; abstr 9500).

[15] Kelleher FC, McDermott R. The emerging pathogenic and therapeutic importance of the anaplastic lymphoma kinase gene. Eur J Cancer. 2010 Sep;46(13):2357-68. Epub 2010 May 5.

[16] Morris SW, Kirstein MN, Valentine MB, Dittmer KG, Shapiro DN, Saltman DL, Look AT. Fusion of a kinase gene, ALK, to a nucleolar protein gene, NPM, in non-Hodgkin's lymphoma. Science. 1994 Mar 4;263(5151):1281-4.

[17] Soda M, Choi YL, Enomoto M, Takada S, Yamashita Y, Ishikawa S, Fujiwara S, Watanabe H, Kurashina K, Hatanaka H, Bando M, Ohno S, Ishikawa Y, Aburatani H, Niki T, Sohara Y, Sugiyama Y, Mano H. Identification of the transforming EML4-ALK fusion gene in non-small-cell lung cancer. Nature. 2007 Aug 2;448(7153):561-6.

[18] Griffin CA, Hawkins AL, Dvorak C, Henkle C, Ellingham T, Perlman EJ. Recurrent involvement of 2p23 in inflammatory myofibroblastic tumors. Cancer Res. 1999 Jun 15;59(12):2776-80. 
[19] van Gaal JC, Flucke UE, Roeffen MH, de Bont ES, Sleijfer S, Mavinkurve-Groothuis AM, Suurmeijer AJ, van der Graaf WT, Versleijen-Jonkers YM. Anaplastic lymphoma kinase aberrations in rhabdomyosarcoma: clinical and prognostic implications. J Clin Oncol. 2012 Jan 20;30(3):308-15.

[20] Donahue SP. Clinical practice. Pediatric strabismus. N Engl J Med. 2007 Mar 8;356(10):1040-7.

[21] Keech RV, Kutschke PJ. Upper age limit for the development of amblyopia. J Pediatr Ophthalmol Strabismus. 1995 Mar-Apr;32(2):89-93.

[22] Kwak EL, Bang YJ, Camidge DR, Shaw AT, Solomon B, Maki RG, Ou SH, Dezube BJ, Jänne PA, Costa DB, Varella-Garcia M, Kim WH, Lynch TJ, Fidias P, Stubbs H, Engelman JA, Sequist LV, Tan W, Gandhi L, Mino-Kenudson M, Wei GC, Shreeve SM, Ratain MJ, Settleman J, Christensen JG, Haber DA, Wilner K, Salgia R, Shapiro GI, Clark JW, Iafrate AJ. Anaplastic lymphoma kinase inhibition in non-small-cell lung cancer. N Engl J Med. 2010 Oct 28;363(18):1693-703.

[23] De Preter K, Vandesompele J, Heimann P, Yigit N, Beckman S, Schramm A, Eggert A, Stallings RL, Benoit Y, Renard M, De Paepe A, Laureys G, Påhlman S, Speleman F. Human fetal neuroblast and neuroblastoma transcriptome analysis confirms neuroblast origin and highlights neuroblastoma candidate genes. Genome Biol. 2006;7(9):R84.

[24] Beckwith JB, Perrin EV. In situ neuroblastomas; A contribution to the natural history of neural crest tumors. Am J Pathol. 1963 Dec;43:1089-104.

[25] Knudson AG Jr, Strong LC. Mutation and cancer: neuroblastoma and pheochromocytoma. Am J Hum Genet. 1972 Sep; 24(5):514-32.

[26] Kushner BH, Gilbert F, Helson L. Familial neuroblastoma. Case reports, literature review, and etiologic considerations. Cancer. 1986 May 1;57(9):1887-93.

[27] Maris JM, Kyemba SM, Rebbeck TR, White PS, Sulman EP, Jensen SJ, Allen C, Biegel JA, Brodeur GM. Molecular genetic analysis of familial neuroblastoma. Eur J Cancer. 1997 Oct;33(12):1923-8.

[28] Friedman DL, Kadan-Lottick NS, Whitton J, Mertens AC, Yasui Y, Liu Y, Meadows AT, Robison LL, Strong LC. Increased risk of cancer among siblings of long-term childhood cancer survivors: a report from the childhood cancer survivor study. Cancer Epidemiol Biomarkers Prev. 2005 Aug;14(8):1922-7.

[29] Amiel J, Laudier B, Attié-Bitach T, Trang H, de Pontual L, Gener B, Trochet D, Etchevers H, Ray P, Simonneau M, Vekemans M, Munnich A, Gaultier C, Lyonnet S. Polyalanine expansion and frameshift mutations of the paired-like homeobox gene PHOX2B in congenital central hypoventilation syndrome. Nat Genet. 2003 Apr; 33(4):459-61. Epub 2003 Mar 17. 
[30] Mossé YP, Laudenslager M, Khazi D, Carlisle AJ, Winter CL, Rappaport E, Maris JM. Germline PHOX2B mutation in hereditary neuroblastoma. Am J Hum Genet. 2004 Oct;75(4):727-30.

[31] Mossé YP, Laudenslager M, Longo L, Cole KA, Wood A, Attiyeh EF, Laquaglia MJ, Sennett R, Lynch JE, Perri P, Laureys G, Speleman F, Kim C, Hou C, Hakonarson H, Torkamani A, Schork NJ, Brodeur GM, Tonini GP, Rappaport E, Devoto M, Maris JM. Identification of ALK as a major familial neuroblastoma predisposition gene. Nature. 2008 Oct 16;455(7215):930-5. Epub 2008 Aug 24.

[32] George RE, Sanda T, Hanna M, Fröhling S, Luther W 2nd, Zhang J, Ahn Y, Zhou W, London WB, McGrady P, Xue L, Zozulya S, Gregor VE, Webb TR, Gray NS, Gilliland DG, Diller L, Greulich H, Morris SW, Meyerson M, Look AT. Activating mutations in ALK provide a therapeutic target in neuroblastoma. Nature. 2008 Oct 16;455(7215): 975-8.

[33] Chen Y, Takita J, Choi YL, Kato M, Ohira M, Sanada M, Wang L, Soda M, Kikuchi A, Igarashi T, Nakagawara A, Hayashi Y, Mano H, Ogawa S. Oncogenic mutations of ALK kinase in neuroblastoma. Nature. 2008 Oct 16;455(7215):971-4.

[34] Greulich H, Chen TH, Feng W, Jänne PA, Alvarez JV, Zappaterra M, Bulmer SE, Frank DA, Hahn WC, Sellers WR, Meyerson M. Oncogenic transformation by inhibitor-sensitive and -resistant EGFR mutants. PLoS Med. 2005 Nov;2(11):e313. Epub 2005 Oct 4.

[35] Lynch TJ, Bell DW, Sordella R, Gurubhagavatula S, Okimoto RA, Brannigan BW, Harris PL, Haserlat SM, Supko JG, Haluska FG, Louis DN, Christiani DC, Settleman J, Haber DA. Activating mutations in the epidermal growth factor receptor underlying responsiveness of non-small-cell lung cancer to gefitinib. N Engl J Med. 2004 May 20;350(21):2129-39. Epub 2004 Apr 29.

[36] Paez JG, Jänne PA, Lee JC, Tracy S, Greulich H, Gabriel S, Herman P, Kaye FJ, Lindeman N, Boggon TJ, Naoki K, Sasaki H, Fujii Y, Eck MJ, Sellers WR, Johnson BE, Meyerson M. EGFR mutations in lung cancer: correlation with clinical response to gefitinib therapy. Science. 2004 Jun 4;304(5676):1497-500. Epub 2004 Apr 29.

[37] Vogelstein B, Kinzler KW. Cancer genes and the pathways they control. Nat Med. 2004 Aug;10(8):789-99.

[38] Fix A, Lucchesi C, Ribeiro A, Lequin D, Pierron G, Schleiermacher G, Delattre O, Janoueix-Lerosey I. Characterization of amplicons in neuroblastoma: high-resolution mapping using DNA microarrays, relationship with outcome, and identification of overexpressed genes. Genes Chromosomes Cancer. 2008 Oct;47(10):819-34.

[39] De Brouwer S, De Preter K, Kumps C, Zabrocki P, Porcu M, Westerhout EM, Lakeman A, Vandesompele J, Hoebeeck J, Van Maerken T, De Paepe A, Laureys G, Schulte JH, Schramm A, Van Den Broecke C, Vermeulen J, Van Roy N, Beiske K, Renard M, Noguera R, Delattre O, Janoueix-Lerosey I, Kogner P, Martinsson T, Naka- 
gawara A, Ohira M, Caron H, Eggert A, Cools J, Versteeg R, Speleman F. Metaanalysis of neuroblastomas reveals a skewed ALK mutation spectrum in tumors with MYCN amplification. Clin Cancer Res. 2010 Sep 1;16(17):4353-62. Epub 2010 Aug 18.

[40] Bresler SC, Wood AC, Haglund EA, Courtright J, Belcastro LT, Plegaria JS, Cole K, Toporovskaya Y, Zhao H, Carpenter EL, Christensen JG, Maris JM, Lemmon MA, Mossé YP. Differential inhibitor sensitivity of anaplastic lymphoma kinase variants found in neuroblastoma. Sci Transl Med. 2011 Nov 9;3(108):108ra114.

[41] Oster SK, Ho CS, Soucie EL, Penn LZ. The myc oncogene: MarvelouslY Complex. Adv Cancer Res. 2002;84:81-154.

[42] Soucek L, Evan GI. The ups and downs of Myc biology. Curr Opin Genet Dev. 2010 Feb;20(1):91-5.

[43] Fernandez PC, Frank SR, Wang L, Schroeder M, Liu S, Greene J, Cocito A, Amati B. Genomic targets of the human c-Myc protein. Genes Dev. 2003 May 1;17(9):1115-29. Epub 2003 Apr 14.

[44] O'Connell BC, Cheung AF, Simkevich CP, Tam W, Ren X, Mateyak MK, Sedivy JM. A large scale genetic analysis of c-Myc-regulated gene expression patterns. J Biol Chem. 2003 Apr 4;278(14):12563-73. Epub 2003 Jan 14.

[45] Soucek L, Whitfield J, Martins CP, Finch AJ, Murphy DJ, Sodir NM, Karnezis AN, Swigart LB, Nasi S, Evan GI. Modelling Myc inhibition as a cancer therapy. Nature. 2008 Oct 2;455(7213):679-83.

[46] Soucek L, Helmer-Citterich M, Sacco A, Jucker R, Cesareni G, Nasi S. Design and properties of a Myc derivative that efficiently homodimerizes. Oncogene. 1998 Nov 12;17(19):2463-72.

[47] Soucek L, Jucker R, Panacchia L, Ricordy R, Tatò F, Nasi S. Omomyc, a potential Myc dominant negative, enhances Myc-induced apoptosis.Cancer Res. 2002 Jun 15;62(12): 3507-10.

[48] Weiss WA, Aldape K, Mohapatra G, Feuerstein BG, Bishop JM. Targeted expression of MYCN causes neuroblastoma in transgenic mice. EMBO J. 1997 Jun 2;16(11): 2985-95.

[49] Schwab M, Alitalo K, Klempnauer KH, Varmus HE, Bishop JM, Gilbert F, Brodeur G, Goldstein M, Trent J. Amplified DNA with limited homology to myc cellular oncogene is shared by human neuroblastoma cell lines and a neuroblastoma tumour. Nature. 1983 Sep 15-21;305(5931):245-8.

[50] Maris JM, Weiss MJ, Mosse Y, Hii G, Guo C, White PS, Hogarty MD, Mirensky T, Brodeur GM, Rebbeck TR, Urbanek M, Shusterman S. Evidence for a hereditary neuroblastoma predisposition locus at chromosome 16p12-13. Cancer Res. 2002 Nov 15;62(22):6651-8. 
[51] Reiter JL, Brodeur GM. High-resolution mapping of a 130-kb core region of the MYCN amplicon in neuroblastomas. Genomics. 1996 Feb 15;32(1):97-103.

[52] Reiter JL, Brodeur GM. MYCN is the only highly expressed gene from the core amplified domain in human neuroblastomas. Genes Chromosomes Cancer. 1998 Oct; 23(2):134-40.

[53] Chanthery YH, Gustafson WC, Itsara M, Persson A, Hackett CS, Grimmer M, Charron E, Yakovenko S, Kim G, Matthay KK, Weiss WA. Paracrine signaling through MYCN enhances tumor-vascular interactions in neuroblastoma. Sci Transl Med. 2012 Jan 4;4(115):115ra3.

[54] Chesler L, Schlieve C, Goldenberg DD, Kenney A, Kim G, McMillan A, Matthay KK, Rowitch D, Weiss WA. Inhibition of phosphatidylinositol 3-kinase destabilizes Mycn protein and blocks malignant progression in neuroblastoma. Cancer Res. 2006 Aug 15;66(16):8139-46.

[55] Hogarty MD, Maris JM. PI3King on MYCN to improve neuroblastoma therapeutics. Cancer Cell. 2012 Feb 14;21(2):145-7.

[56] Brodeur GM, Seeger RC, Schwab M, Varmus HE, Bishop JM. Amplification of N-myc in untreated human neuroblastomas correlates with advanced disease stage. Science. 1984 Jun 8;224(4653):1121-4.

[57] Liu Z, Thiele CJ. ALK and MYCN: when two oncogenes are better than one. Cancer Cell. 2012 Mar 20;21(3):325-6.

[58] Schönherr C, Ruuth K, Kamaraj S, Wang CL, Yang HL, Combaret V, Djos A, Martinsson T, Christensen JG, Palmer RH, Hallberg B. Anaplastic Lymphoma Kinase (ALK) regulates initiation of transcription of MYCN in neuroblastoma cells.Oncogene. 2012 Jan 30 .

[59] Zhu S, Lee JS, Guo F, Shin J, Perez-Atayde AR, Kutok JL, Rodig SJ, Neuberg DS, Helman D, Feng H, Stewart RA, Wang W, George RE, Kanki JP, Look AT. Activated ALK collaborates with MYCN in neuroblastoma pathogenesis. Cancer Cell. 2012 Mar 20;21(3):362-73.

[60] Schönherr C, Ruuth K, Yamazaki Y, Eriksson T, Christensen J, Palmer RH, Hallberg B. Activating ALK mutations found in neuroblastoma are inhibited by Crizotinib and NVP-TAE684. Biochem J. 2011 Dec 15;440(3):405-13.

[61] Matthay KK, Villablanca JG, Seeger RC, Stram DO, Harris RE, Ramsay NK, Swift P, Shimada H, Black CT, Brodeur GM, Gerbing RB, Reynolds CP. Treatment of highrisk neuroblastoma with intensive chemotherapy, radiotherapy, autologous bone marrow transplantation, and 13-cis-retinoic acid. Children's Cancer Group. N Engl J Med. 1999 Oct 14;341(16):1165-73.

[62] George RE, Li S, Medeiros-Nancarrow C, Neuberg D, Marcus K, Shamberger RC, Pulsipher M, Grupp SA, Diller L. High-risk neuroblastoma treated with tandem au- 
tologous peripheral-blood stem cell-supported transplantation: long-term survival update. J Clin Oncol. 2006 Jun 20;24(18):2891-6.

[63] Maris JM. Recent advances in neuroblastoma. N Engl J Med. 2010 Jun 10; 362(23): 2202-11.

[64] Maris JM, Matthay KK. Molecular biology of neuroblastoma. J Clin Oncol. 1999 Jul; 17(7):2264-79.

[65] Lastowska M, Cullinane C, Variend S, Cotterill S, Bown N, O'Neill S, Mazzocco K, Roberts P, Nicholson J, Ellershaw C, Pearson AD, Jackson MS; United Kingdom Children Cancer Study Group and the United Kingdom Cancer Cytogenetics Group. Comprehensive genetic and histopathologic study reveals three types of neuroblastoma tumors. J Clin Oncol. 2001 Jun 15;19(12):3080-90.

[66] Kushner BH, Cheung NK.Treatment reduction for neuroblastoma. Pediatr Blood Cancer. 2004 Nov;43(6):619-21

[67] Kushner BH, Kramer K, LaQuaglia MP, Modak S, Cheung NK. Liver involvement in neuroblastoma: the Memorial Sloan-Kettering Experience supports treatment reduction in young patients. Pediatr Blood Cancer. 2006 Mar;46(3):278-84.

[68] Shimada H, Ambros IM, Dehner LP, Hata J, Joshi VV, Roald B, Stram DO, Gerbing RB, Lukens JN, Matthay KK, Castleberry RP. The International Neuroblastoma Pathology Classification (the Shimada system). Cancer. 1999 Jul 15;86(2):364-72.

[69] Shimada H, Umehara S, Monobe Y, Hachitanda Y, Nakagawa A, Goto S, Gerbing RB, Stram DO, Lukens JN, Matthay KK. International neuroblastoma pathology classification for prognostic evaluation of patients with peripheral neuroblastic tumors: a report from the Children's Cancer Group. Cancer. 2001 Nov 1;92(9):2451-61.

[70] Goto S, Umehara S, Gerbing RB, Stram DO, Brodeur GM, Seeger RC, Lukens JN, Matthay KK, Shimada H. Histopathology (International Neuroblastoma Pathology Classification) and MYCN status in patients with peripheral neuroblastic tumors: a report from the Children's Cancer Group. Cancer. 2001 Nov 15;92(10):2699-708.

[71] Peuchmaur M, d'Amore ES, Joshi VV, Hata J, Roald B, Dehner LP, Gerbing RB, Stram DO, Lukens JN, Matthay KK, Shimada H. Revision of the International Neuroblastoma Pathology Classification: confirmation of favorable and unfavorable prognostic subsets in ganglioneuroblastoma, nodular. Cancer. 2003 Nov 15;98(10):2274-81.

[72] Matthay KK, Reynolds CP, Seeger RC, Shimada H, Adkins ES, Haas-Kogan D, Gerbing $\mathrm{RB}$, London $\mathrm{WB}$, Villablanca JG. Long-term results for children with high-risk neuroblastoma treated on a randomized trial of myeloablative therapy followed by 13-cis-retinoic acid: a children's oncology group study. J Clin Oncol. 2009 Mar 1;27(7): 1007-13. Epub 2009 Jan 26.

[73] Yu AL, Gilman AL, Ozkaynak MF, London WB, Kreissman SG, Chen HX, Smith M, Anderson B, Villablanca JG, Matthay KK, Shimada H, Grupp SA, Seeger R, Reynolds 
CP, Buxton A, Reisfeld RA, Gillies SD, Cohn SL, Maris JM, Sondel PM; Children's Oncology Group. Anti-GD2 antibody with GM-CSF, interleukin-2, and isotretinoin for neuroblastoma. N Engl J Med. 2010 Sep 30;363(14):1324-34.

[74] Ladenstein RL, et al.: Busulphan-melphalan as a myeloablative therapy (MAT) for high-risk neuroblastoma: Results from the HR-NBL1/SIOPEN trial. Presented at the $47^{\text {th }}$ Annual Meeting of the American Society of Clinical Oncology: June 2011; Chicago, IL.

[75] Baker DL, Schmidt ML, Cohn SL, Maris JM, London WB, Buxton A, Stram D, Castleberry RP, Shimada H, Sandler A, Shamberger RC, Look AT, Reynolds CP, Seeger RC, Matthay KK; Children's Oncology Group. Outcome after reduced chemotherapy for intermediate-risk neuroblastoma. N Engl J Med. 2010 Sep 30;363(14):1313-23.

[76] Nickerson HJ, Matthay KK, Seeger RC, Brodeur GM, Shimada H, Perez C, Atkinson JB, Selch M, Gerbing RB, Stram DO, Lukens J. Favorable biology and outcome of stage IV-S neuroblastoma with supportive care or minimal therapy: a Children's Cancer Group study. J Clin Oncol. 2000 Feb;18(3):477-86.

[77] Schmidt ML, Lukens JN, Seeger RC, Brodeur GM, Shimada H, Gerbing RB, Stram DO, Perez C, Haase GM, Matthay KK. Biologic factors determine prognosis in infants with stage IV neuroblastoma: A prospective Children's Cancer Group study. J Clin Oncol. 2000 Mar;18(6):1260-8.

[78] Matthay KK, Perez C, Seeger RC, Brodeur GM, Shimada H, Atkinson JB, Black CT, Gerbing R, Haase GM, Stram DO, Swift P, Lukens JN. Successful treatment of stage III neuroblastoma based on prospective biologic staging: a Children's Cancer Group study. J Clin Oncol. 1998 Apr;16(4):1256-64.

[79] Mertz JA, Conery AR, Bryant BM, Sandy P, Balasubramanian S, Mele DA, Bergeron L, Sims RJ 3rd. Targeting MYC dependence in cancer by inhibiting BET bromodomains. Proc Natl Acad Sci U S A. 2011 Oct 4;108(40):16669-74. Epub 2011 Sep 26.

[80] Westermann F, Muth D, Benner A, Bauer T, Henrich KO, Oberthuer A, Brors B, Beissbarth T, Vandesompele J, Pattyn F, Hero B, König R, Fischer M, Schwab M. Distinct transcriptional MYCN/c-MYC activities are associated with spontaneous regression or malignant progression in neuroblastomas. Genome Biol. 2008 Oct 13;9(10):R150.

[81] Schulte JH, Lindner S, Bohrer A, Maurer J, De Preter K, Lefever S, Heukamp L, Schulte S, Molenaar J, Versteeg R, Thor T, Künkele A, Vandesompele J, Speleman F, Schorle H, Eggert A, Schramm A. MYCN and ALKF1174L are sufficient to drive neuroblastoma development from neural crest progenitor cells. Oncogene. 2012 Apr 9. 
